\title{
Study on Path of Science Popularization Innovation of University Science Associate Under the New Situation
}

\author{
Ling Ou, Huixiang Liu, Yali Lu, Xiuli Chen, Zhenglun Wang \\ Science and Technology Association, Huazhong University of Science and Technology, Wuhan, Hubei, China
}

Email address:

ouling@hust.edu.cn (Ling Ou), huixl@hust.edu.cn (Huixiang Liu)

\section{To cite this article:}

Ling Ou, Huixiang Liu, Yali Lu, Xiuli Chen, Zhenglun Wang. Study on Path of Science Popularization Innovation of University Science Associate Under the New Situation. Science Innovation. Vol. 4, No. 3, 2016, pp. 151-155. doi: 10.11648/j.si.20160403.16

Received: April 14, 2016; Accepted: June 12, 2016; Published: June 15, 2016

\begin{abstract}
University Science Associate, which has dual identity of both university and association for science and technology , is the main functional departments of Chinese universities to carry out the science popularization work. The paper systematic research University Science Associate using the popular science lectures, competition, and forming scientific camp to carry out the science popularization work of science by Case and inductive analysis method etc.In the study, we found University Science Associate had, such as the form of a single, talent training is not enough, the lack of innovation. On the basis, the paper, trying to combine the new situation, should take its advantages in the aspects like intelligence, audience, site, organization etc. to carry out science popularization work innovatively via innovating concept, broadening thought, cultivating talents, innovating work mode and so on under new situation.
\end{abstract}

Keywords: University Science Associate, Scientific Popularization, Innovation, Path

\section{新形势下高校科协创新科普工作路径研究}

欧玲, 柳会祥, 鲁亚莉, 陈秀丽, 王正伦

华中科技大学科学技术协会, 武汉, 湖北, 中国

邮箱

ouling@hust. edu. cn（欧玲）, huixl@hust. edu.cn（柳会祥）

摘要: 兼具高校与科协双重身份的高校科协是中国高校开展科普工作的主要职能部门。本文运用案例、归纳等分析方 法对高校科协运用科普讲座、科技竞赛、科学营等形式开展科普工作进行系统研究, 发现高校科协存在一些诸如形式 单一、人才培养不够、创新乏力等问题。在此基础上, 本文尝试着结合当前新形势, 提出高校科协应结合自身在智力、 受众、场地、组织等方面的优势, 通过理念创新、开拓思路、培养人才及创新工作模式等路径, 创造性地开展科普工 作。

关键词: 高校科协, 科普, 创新, 路径

\section{1. 引言}

科普活动的目标是向普通大众 “普及科学技术知识、 倡导科学方法、传播科学思想、弘扬科学精神”。《中华
人民共和国科学技术普及法》明确规定: “各类学校及其 他教育机构, 应当把科普作为素质教育的重要内容, 组织 
学生开展多种形式的科普活动” ; “高等院校等团体机构 应当组织和支持科学技术工作者和教师开展科普活动, 鼓 励其结合本职工作进行科普宣传”。《中华人民共和国高 等教育法》明确要求 “发展科学技术文化” 列为高等教育 的任务。因此, 高校开展科学普及工作法不容辞。兼具高 校与科协双重身份的高校科协, 是高校开展科普工作的主 要职能部门, 应当在充分发挥高校与科协两方面的组织优 势的基础上, 创造性地开展科普工作。

新形势下, 高校科协创造性开展科普工作是实现创新 型国家的建设, 中国梦的实现的迫切需要 [1]。高校科协 既不能满足在科普方面已取得的成绩, 也应该正视存在的 问题与困难, 要结合实际, 积极发挥高校与科协的组织优 势, 进行开创性的科普工作, 使高校科普工作创出特色、 创出效果, 始终走在科普工作的前列。

\section{2. 高校科协开展科普工作的现状}

《中国科协、教育部关于加强高等学校科协工作的意 见》明确提出, 高校科协主要任务之一是开展科学技术普 及活动, 其主要内容为: 贯彻《全民科学素质行动计划纲 要》, 组织师生面向公众开展科学技术普及活动。运用高 校科普资源, 开放实验室、标本室、博物馆、实验示范基 地等场所, 面向公众普及科学知识。组织师生参与科技周、 科普日、科普征文、科普报告、科普创作等活动。整合大 学生科普志愿者、科普宣讲团、校内科技社团等力量, 深 入社区、农村、企业、学校开展科普服务。该文明确了高 校科协开展科普工作的内容及其主要形式。

\section{1. 高校科协开展科普工作的主要形式}

据调查, 当前高校科协开展科普工作常见形式主要包 括以下几种。

\subsection{1. 科普讲座}

科普讲座是一种近距离的, 面对面的信息传播形式。 一直以来就是高校科协举办科普活动的重要形式之一, 每 年高校都要举办多场次不同内容的科普讲座, 主要对象有 学生, 老师和离退休人员。就讲座的主题, 邀请该领域的 老师或专业人员就该领域某一主题，向师生介绍与此相关 的知识。讲座内容主要以自然科技知识为主, 如: 针对学 生群体的心理讲座; 针对离退休人员的保健健康讲座等等。

\subsection{2. 科技竞赛}

高校科协组织大中小学生的科技竞赛也是举办科普 活动的形式之一。如由著名物理学家, 诺贝尔奖获得者杨 振宁博士创导, 香港亿利达工业发展集团有限公司董事长 刘永龄先生出资在 “四省二市”（湖北、四川、江苏、浙 江、天津、上海）设立了 “亿利达青少年发明奖” , 这项 活动受到中小学师生的热烈欢迎, 每年都收到来自 “四省 二市” 中小学生数百件参赛作品。再如, 有的高校科协, 依托学生社团（如研究生科协、大学生科协等）, 开展大 学生创新创意作品大赛活动, 评选出优秀作品并推荐为参 加中国科协等举办的全国青少年创新创意大赛参赛作品。
还有的高校科协依托挂靠学会组织科技竞赛。如华中科技 大学科协依托挂靠学会——湖北省力学学会参与组织了 中国力学学会主办的 “全国周培源大学生力学竟赛” 湖北 赛区的工作。这些活动极大地激发了青少年参与科技活动 的热情, 有效培养青少年对科学的兴趣。

\section{1. 3. 高校科学营活动及其它活动}

举办科学营也是高校科协进行科普活动的又一形式。 如由中国科协、教育部共同主办, 中国科学院为支持单位, 全国 40 余所教育部直属重点高校、各省级科协和省级教育 厅 (教委) 共同承办的全国青少年高校科学营活动, 以及 高校内部相关职能部门、院系举办的夏令营、冬令营等活 动, 都取得较好的科普效果。其它诸如支持学生社团开展 学校科技节、下午茶、学术沙龙、学术论坛、组织参观各 种科普展览等活动等。

\section{2. 高校科协科普工作存在的问题}

尽管高校科协立足高校与科协的组织优势, 采取多种 形式开展科普工作, 且取得显著的科普效应, 但是高校科 协科普工作的不足之处也是相当明显, 迫切需要进一步创 新以完善之。

\section{2. 1. 科普形式单一、内容陈旧, 影响范围有限}

从上述高校科协开展科普工作形式来看, 当前高校科 协圊于所处环境, 其主要科普对象主要为在校大中小学生, 加之场地受限, 以致于科普形式创新程度与动力皆不足。 传统并被认为有效的科普形式, 如科普讲座、科技竞赛和 科学营活动被视为高校科协科普工作的固有模式。这些固 有模式日复一日, 年复一年, 历年难有变化, 既不能吸引 更多潜在科普受众, 其科普效应也大打折扣。如科普讲座, 据调查, 各高校讲座形式基本上是授者讲, 受者听, 尽 管都设有互动环节, 但都不够深入, 很难发挥受众在活动 中的主观能动性, 间接影响了活动效果。尽管科技竞赛和 科学营活动形式是传统的、也是有效的, 但由于其受众也 主要局限于小范围的大中小学生, 难以走出校园, 走向社 会, 因而不能达到更大范围传播科技知识, 扩大科普活动 影响力的作用。

\subsection{2. 科普人才培养不力}

科普工作是全方位、系统性的工程, 其所需的各类专 业人才也是相当广泛, 作为高校科普人才, 理应包括科普 行政管理人员和传授科技专业知识的专门人员。高校科协 在各类科普人才培养方面还有待改进之处。主要表现为: (1) 科普行政管理人员的培养重视不够。据了解, 全国 高校科协通常是挂靠在学校的科技处（科发院）, 有很多 学校的科协工作都是由科技处的工作人员兼任, 没有专职 人员, 想要开展科普活动的困难很大。（2）科普知识传 播人才挖掘不够。多数高校科协工作人员主要是行政管理 人员，少有专门的传播科技知识的专业人才。在相当大的 程度上，传播科技知识的人员多是兼职。因此，高校科协 举办科普讲座时只能根据讲座内容邀请相关的专业教师 临时担任。而高校对教师从事科普工作的评价普遍不够重 
视, 严重影响了兼职教师进行科普活动的积极性。

科普高层次人才贯乏 $[2]$ 。目前中国的高校里鲜有培养科 普人才的本科专业。2012年教育部与中国科协联合开展推 进培养高层次科普专门人才试点工作, 首批在清华大学、 北京航空航天大学、北京师范大学、华东师范大学、浙江 大学、华中科技大学等6所高校先期开展培养科普教育人 才、科普产品创意与设计人才、科普传媒人才三个方向的 试点工作, 试点工作培养目标是具有科普场馆及相关行业 各类展览与教育活动等科普产品的设计开发、理论研究、 组织实施与项目管理能力的高素质复合型人才 [3]。这无 异于打开了科普人才队伍培养的大门, 但对于中国庞大的 科普活动规模, 也还是杯水车薪。而对于科普活动中的核 心人员：传授专业知识的人才仍然没有涉及。

\subsection{3. 对与科技相关的社会热点问题关注不足}

社会发展到当今的互联网时代, 热点问题层出不穷, 与科技相关的社会热点问题也不在少数。2016年才刚刚过 去四分之一, 就有很多让公众应接不暇并引起极大关注的 热点事件, 如 2 月的华阴老腔热潮、引力波事件、3月围棋 人机大战、毒疫苗等事件。公众对这些事件给予极大的热 情和好奇, 对于大多数人来说, 面对这些充满了未知数的 事件, 迫切需要了解与此相关的科技知识和人文知识。但 据了解, 由于对与科技相关的社会热点问题关注不足 [4], 目前还没有高校科协就这些公众关注的社会热点问题进 行跟进, 更没有进行及时的科普活动。

\section{3. 高校科协创新科普工作的优势}

高校科协创新科普工作有其得天独厚的优势, 主要表 现在以下几个方面。

\section{1 . 智力优势}

高校科协是校党委领导下的科技工作者的群众性学 术体，是 “科技工作者之家”。而高校聚集了众多拥有各 学科背景的科技工作者, 这就为不同主题的科普活动提供 了丰富的人才优势。高校科协作为连接各类科技工作者的 平台, 应主动发挥自身优势, 使得不同领域人才的专业知 识和技能能够在科学普及工作上发挥最大的优势。

\section{2. 受众优势}

高校科协科普活动面对的主要对象是大学生, 研究生, 离退休人员等, 这个群体受教育程度比较高, 科学素养也 相对社会其它群体高, 对学习新知识有主动性, 对未知事 物比较强烈的求知欲, 与科普想要达成的目标有比较高的 契合度。

\section{3. 场地优势}

高校拥有校史馆、图书馆、科研设施、众多的实验室 和校园网络。2007年国家多部委联合发布的《关于科研机 构和大学向社会开放开展科普活动的若干意见》明确指出, 科研机构和大学将科研设施、场所等科技资源向社会开放 开展科普活动, 科研机构和大学向社会开放要坚持公益性
原则, 突出社会效益。因此高校在全国科普日、校园开放 日、科技周等特殊日子向社会公众开放这些场馆和设施, 有利于大力进行科普宣传和科普活动。

\section{4. 组织优势}

在科普组织工作方面, 高校科协有为数众多的各类挂 靠学会可以依托。挂靠学会是高校科协的一支主力军, 学 会里聚集了众多的行业专家, 高校科协利用这个平台, 与 学会协同作战, 强强联合, 做强做大做好科普工作。此外, 各类学生社团也是高校较于社会团体而言不能比拟的优 势, 高校科协可通过和学生社团合作的方式, 打造一支规 模较大的科普志愿者队伍, 使得更多拥有专业知识的年轻 学生, 通过发挥他们对待科学的热情及思维的敏锐性, 积 极地参与到科普队伍当中来, 这将对高校科协科普工作的 开展大有禆益。

\section{4. 高校科协创新科普工作的对策}

21 世纪作为信息爆炸的互联网 ${ }^{+}$时代, 与公众息息相 关的科学、文化、艺术等领域的热点问题层出不穷, 公众 环境与公众关注的焦点也在不断变换。面对如此众多良莠 不齐、似是而非、真伪难辨的信息, 公众群体难免应接不 暇, 无法分辨。高校科协在新形势下, 面对复杂的受众环 境, 开展科普活动要创新理念、开拓思路、培养科普人才、 创新模式, 才能让科普活动更有活力和吸引力。

\section{1 . 创新理念}

创新理念是高校科协创新科普工作的关键。当前科普 不仅是科学技术的传播, 还有社会科学知识的传播, 更重 要的是向公众传播科学方法、科学思想、科学精神。高校 科协要从理念上摒弃科普就是科技知识的传播的观念, 扩 大科普活动主题范围: 人文、社会、历史、哲学、艺术等 等。这样既有利于科普对象在接受科技知识的同时, 也加 强对人文知识的学习, 让科普工作从主要以传播科技知识 为主转变为既传播知识也传播文化, 把 “倡导科学方法、 传播科学思想、弘扬科学精神” 的理念始终贯穿于科普活 动中。

\section{2. 开拓思路}

开拓思路是高校科协创新科普工作的突破口。当前开 拓思路主要从以下方面进行。

\section{2. 1. 结合热点问题开展科普工作}

当前高校科协除了做好传统的科普工作, 更应积极关 注当下的社会热点问题, 结合热点问题开展科普工作 [5]。 因为热点问题可以为科普工作提供鲜活而丰富的素材。如 “引力波” 事件, 可以提供科学史、物理学、天文学的知 识; “民间科学家” 引起的争议, 除了可以提供科学与伪 科学甄别的知识, 还可以提供心理学的知识; “华阴老腔” 则可以提供中华民族历史、民风、民俗和民族音乐的知识; 2016年由人工智能系统AlphaGo, 挑战世界围棋冠军李世 石的人机世纪大战提供的不仅是围棋知识, 还有人工智能、 
机器人、人类未来等方面的知识; 而毒疫苗事件则可以提 供医学、防疫、危机管理等方面的知识。更重要的是这些 热点事件是公众关注的焦点, 他们对层出不穷的新鲜事充 满了疑惑和求知欲。所谓兴趣是最好的老师，公众对热点 问题有着强烈的好奇和浓厚的兴趣, 高校科协要顺应时代 潮流，把握公众心理倾向，回应公众关注的焦点，及时传 播公众急需的知识, 解答他们的疑惑, 满足他们的求知欲, 只有这样才能更好提高公众的科学素养。

\section{2. 2. 精准把握科普契入点}

在当今互联网+的时代, 高校科协科普工作可借鉴新 闻报导形式, 注重时效性, 影响力和显赫度 [6], 同时, 要精准把握好科普工作的契入点。这要求高校科协及时了 解受众环境, 有针对性地开展科普活动; 要敏锐抓取一些 公众当下关注的社会热点事件, 适时组织专业人员, 撰写 与此相关的科普文章, 通过校园网和科协网站等线上媒介 平台, 第一时间把相关的科技知识传播给大众, 以便于在 瞬息万变的信息时代, 增强高校科协科普活动的影响力。

\section{2. 3. 着力培养科普人才}

科普人才是高校科协创新科普工作的强力支撑。长期 以来，高校科协科普工作一般只提及科普资源整合、科普 资金投入、科普场馆建设，而科普人才队伍的建设这个最 核心的问题往往被忽略。具体到高校科协, 科普专业人才 除了科普行政管理人员, 还应理解为包括专门从事科技知 识传授的具备专业资格的人员 [7]。因此高校科协着力培 养科普人才, 首先, 依托 “科技工作者之家” 这个平台, 逐步建立、完善科普专家库, 打造一支 “招之即来, 来之 能战, 战之有效” 的兼职科普人员队伍。其次, 大力促成 高校建立一支专职科普队伍, 培养专业化的人才, 打造职 业化的队伍。可以考虑把一些致力于科普事业的各门类专 业技术人员转为专职的, 在职称评定、福利待遇等方面为 他们争取应有的权益。最后, 也是最重要的是培养科普专 业的后备人才, 建议教育部出台政策, 在高校新增科普传 播和科普教育专业, 文理兼招, 课程应涵盖理工农医管以 及哲学社会学心理学新闻学等, 为高校日益繁荣的科普活 动培养一批有各学科门类知识背景的专业人才。

\section{3. 模式创新}

模式创新是高校科协创新科普工作的主要载体。有了 新的工作理念和工作思路, 还要有新的工作模式, 才能适 应当下公众的科普需求。

\section{3. 1. 高校科协要对传统的科普模式注入新的元素}

如科普讲座要处理好授者与受者的关系, 改变授者灌 输, 受者被动接受的简单方式, 授者除了传授专业知识, 也要允许受众提出质疑, 因为真正的科学是经得起质疑的, 而质疑是培养科学精神的核心。授者与受者的良性互动会 对科普知识的传播带来更好的效果。与此同时, 高校科协 还可以简报的形式向公众发放讲座内容, 以扩大受众面, 增强科普效果。科学营除了传统的参观科普场馆、动手制 作科技产品、聆听大师讲座等形式外, 也可以考虑把科技
和人文知识融入歌舞、戏剧、书法、绘画、音频、视频等 丰富多彩的、让青少年更乐于接受的形式之中。

\section{3. 2. 高校科协要善于 “借势”}

首先, 高校科协要紧跟时代潮流, 借助互联网 + , 充 分利用校园网的优势, 进行形式多样的科普活动。比如, 除了传统的讲座、科学营、科技竞赛、参观科普场馆等模 式, 还可以采用公众喜闻乐见的方式, 如音乐、歌曲、舞 蹈、书法、绘画等, 把科普内容融入其中, 让科普知识更 快更好更大范围的传播出去。其次, 采取请进来, 走出去 的方式, 将社会各届专业人士请进大学, 请进课堂, 请进 高校科普活动场所, 以帮助学生更好地开拓视野, 扩大知 识面; 组织校内的专、兼职科技人员和大学生科普志愿者 走出校门, 深入社区、农村、企业、中小学等, 把 “象牙 塔” 里的知识, 以通俗易懂的方式, 面向社会公众开展科 普活动, 帮助公众提高科学素养。

\section{3. 3. 高校科协要大力倡导纸质阅读}

相对于互联网、电子书等新媒介, 传统的纸质出版物 对科学精神、科学思维和科学方法的传播也同样有着不可 比拟的作用。“倡导全民阅读”三次写进政府工作报告 [8], 高校科协 “倡导全民阅读” 有利于引导公众将阅读 “深” 起来, 有利于科学家把科普工作当作已任, 有利于组织专 家把他们的研究成果用科普文章的形式记录下来。中国著 名科学家、科普作家高士其写下了数百万字的科学小品、 科学童话故事和多种形式的科普文章, 引导了一批又一批 青少年走上科学道路 [9]。英国理论物理学家霍金撰写的 《时间简史》自1998年首版以来, 已成为全球科普的里程 碑。它被翻译成 40 多种文字, 销售了 1000 万册, 成为国际 出版史上的奇迹 $[10]$ 。他们都是知名科学家参与科普活动 的典范, 为科普工作做出了巨大贡献。

\section{结语}

社会总是不以人的意志为转移而向前发展的, 而推动 社会向前发展的核心动力是科学技术, 而科学技术发展的 核心是创新, 创新的基础是民众的科学素养。而科学素养 的培养除了学校的知识传播以外, 主要依托校内、外的科 学普及工作, 因此高校科协在科学素养的培养中发挥着不 可替代的作用。对此, 高校科协在日益繁荣的科普工作中, 应发挥其智力、受众、场地、组织的优势, 紧跟时代潮流, 通过创新工作理念, 工作思维和工作方式, 丰富高校科协 科普工作的形式, 全方面培养各类人才, 为逐步提高中国 公民科学素养做出应有的贡献。

\section{参考文献}

［1］郎杰斌等. 对高校开展科普工作的思考 [J], 图书馆与图书 馆事业, 2014(3) :60-63。 
[2] 吕鹏飞, 吴琼石. 国内科普人才现状及培养策略研究 [J], 前沿, 2015(8) : 127-129。

[3] 黄䒯. 首批 30 名科普硕士 2015 年出师 $[\mathrm{N}]$, 长江日 报, 2014-3-13。

[4] 徐顽强, 张红方. 科学普及与社会热点事件的效应扩散 [J], 武汉理工大学学报 (社会科学版), 2011 (6) : 806-809。

[5] 张红方. 我国社会热点事件与科学普及的互动关系研究 [D], 华中科技大学, 2012年6月。

[6] 高钢. 新闻写作精要 [M], 北京: 首都经济贸易大学出版 社, 2005年第1版。
[7] 郑念. 我国科普人才队伍存在的问题及对策研究 [J], 科普 研究, 2009 (2) : 17-29。

８］孙海悦。“全民阅读”第三次写入政府工作报告 [EB/OL]http://www. bi senet. com/article/201603/15696 4. htm, 2016-03-07

[9] 江迪. 科学正在这里交给人民一一苏州打造高士其系列科 普品牌纪实 $[\mathrm{N}]$ ，人民政协报2015-11-04期12版。

[10］许明贤、吴忠超. 时间简史 (序) [M] , 长沙：湖南科学技 术出版社，2015年4月第一版。 